\title{
A method for praecordial surface mapping of the exercise electrocardiogram ${ }^{1}$
}

\author{
K. M. FOX, A. P. SELWYN, AND J. P. SHILLINGFORD \\ From the Division of Cardiovascular Disease, Royal Postgraduate Medical School, Du Cane Road, London
}

SUMMARY A technique for praecordial surface mapping of the exercise electrocardiogram is described. This showed the area, time course, and severity of ST segment depression as projected onto the front of the chest after exercise.

Twenty normal volunteers and 20 patients with coronary artery disease have been studied. No changes were seen after exercise in the normal subjects but areas of ST segment depression appeared in all 20 patients with angina pectoris. In 5 of the 20 patients with coronary artery disease, the exercise test was repeated on a later date. There were no significant differences in the area or severity of electrocardiographic abnormalities recorded during the two tests.

This technique may prove to be useful for diagnosis and assessing medical and surgical treatments in patients with ischaemic heart disease.

Praecordial surface mapping during acute myocardial infarction was initially described by Reid $e t$ $a l$. in 1971. Since that time this technique has been used to define the changes of ST segments, $R$ and $Q$ waves in this condition (Selwyn and Shillingford, 1977; Selwyn et al., 1977, 1978). Few attempts to apply this technique to exercise testing have been tried. The difficulties have centred around the time taken to perform a surface electrocardiogram and the design of an adequate electrode system which is stable even during severe exertion.

Consequently, other workers have used a multichannel electrocardiographic recorder on line to a computer (Block et al., 1976). This is expensive and will be confined to a few selected research centres. The purpose of the present study is to describe a technique of praecordial mapping of the exercise electrocardiogram that uses conventional equipment available in most hospitals.

\section{Subjects and methods}

Twenty normal volunteers ( 16 men, 4 women) aged between 27 and 74 years (mean 46.5 years) and 20 patients with angina pectoris (18 men, 2 women) aged between 41 and 63 years (mean 51 years) were studied. The diagnosis of coronary artery disease

${ }^{1}$ This work was supported by a grant from the British Heart Foundation.

Received for publication 10 February 1978 was established by selective coronary arteriography. Routine 12 lead electrocardiograms and exercise electrocardiograms (using a modified Frank orthogonal system) were recorded in patients with ischaemic heart disease (Frank, 1956; Kilpatrick, 1976).

Praecordial exercise electrocardiograms were recorded using a direct writing ink jet Mingograf (Elema-Schonander) recording on 4 channels simultaneously. The gain employed was $10 \mathrm{~mm}$ for $1 \mathrm{mV}$ and the paper speed was $25 \mathrm{~mm}$ per second. Sixteen points were marked on the chest using an indelible pen, and were distributed evenly over the left hemithorax. The boundaries were the angle of Louis, the right sternoclavicular joint, the posterior axillary line, and $6 \mathrm{~cm}$ below the xiphisternum (Fig. 1). Disposable press stud electrodes were used and then secured into position using adhesive tape sufficiently tight to keep the electrodes stable in position but not such as to interfere with respiration. A specially designed switching box (4 channels switching 4 ways) was used in order to connect 16 screened electrode cables with press stud ends to the 4 channel electrocardiograph machine (Fig. 2). The 16 praecordial electrocardiographic leads were unipolar $\mathrm{V}$ leads connected to a central Wilson terminal.

Each patient performed an increasing work load on a bicycle ergometer (Lanooy and Bonjer, 1956) using a standardised procedure. The exercise tests were limited by the appearance of chest pain, dyspnoea, fatigue, or multiple ventricular ectopic 


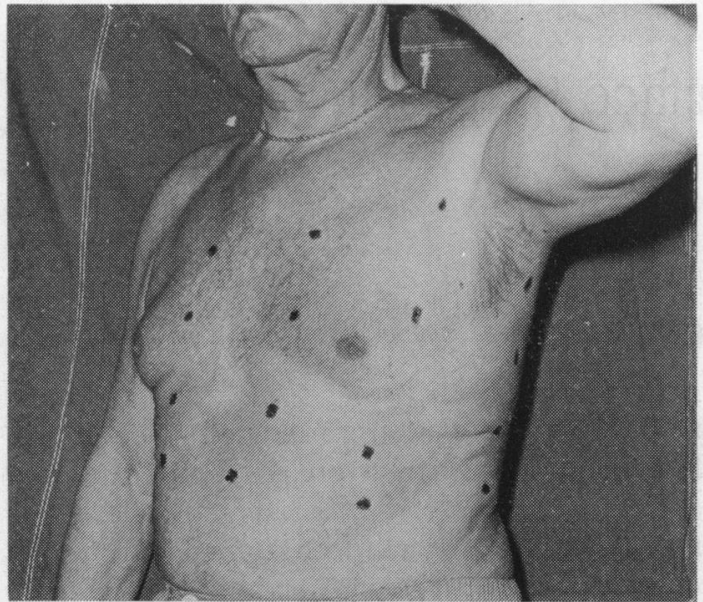

Fig. 1 The 16 points from which exercise praecordial electrocardiagrams are recorded.

beats. All recordings were made with the patient sitting comfortably with the arms extended resting on the handlebars. A recording of the 16 leads was made before exercise, immediately after, and then $1,3,5,8$, and 10 minutes later. Recordings were then continued at 3-minute intervals, as necessary, until the electrocardiogram had returned to the preexercise state. The electrocardiogram was continually monitored during the test and resuscitation equipment was available.

Connecting the patient up took 10 to 15 minutes and usually 15 to 20 minutes was required for the exercise test and post-exercise recordings. Each 16 lead praecordial map took about 10 seconds to record. About 10 minutes was required to analyse a series of maps from a patient.

INTERPRETATION OF RECORDS

The usual criteria for the interpretation of exercise

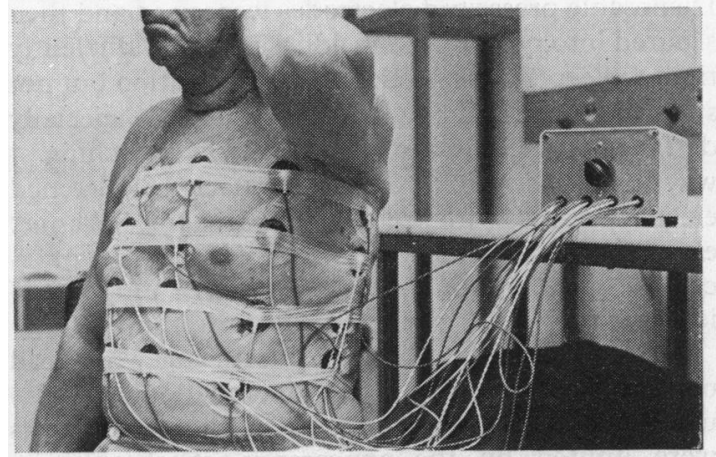

Fig. 2 The 16 praecordial electrodes are connected to a 4-channel switching box. electrocardiograms were used (Scandinavian Committee on ECG classification, 1967). At each of the 16 positions planar ST segment depression was measured. At each position the ST segment changes measured in 3 complexes were noted and an average taken. In each patient either the TP or the PQ segment was used as the isoelectric line. The choice depended upon which of these remained identifiable before and after exercise. ST segment depression was measured in $\mathrm{mm}$ to the nearest $0.5 \mathrm{~mm}$. The ST segment was considered to be depressed if there was a change of $1.0 \mathrm{~mm}$ or more lasting for $0.08 \mathrm{~s}$ or longer (Myers and Talmers, 1955; Mason and Likar, 1966).

Contour maps of the area of ST segment depression for each recording were drawn (Selwyn et al., 1977). On average, less than 5 minutes was required to draw each sequence of contour maps.

\section{REPRODUCIBILITY}

In 5 patients with coronary artery disease, praecordial exercise surface mapping was repeated on a separate day. Each patient was exercised to the same work load and a comparison was made between the area and severity of ST segment depression recorded on the two days.

\section{Results}

Recordings of sufficient quality to measure changes in the ST segment were obtained in all patients. A typical example of a recording taken before and immediately after exercise is shown in Fig. 3. While respiratory swing was present in 9 of the 40 patients immediately after exercise, it was possible to overcome this by recording at least 3 heart beats at end tidal volume. All the electrodes remained in position, in spite of maximal exercise. It was not necessary to shave the chests of the men to obtain a satisfactory tracing, nor were any difficulties experienced in the 6 women.

\section{NORMAL SUBJECTS}

The maximum heart rates achieved in these 20 patients were 111 to 167 beats/minute (mean 147 beats/minute). The mean work load reached was 168 watts at $50 \mathrm{rpm}$ for 6 minutes. The heart rate in all patients had returned to within \pm 5 per cent of the resting level within 10 minutes of the end of exercise. No ST segment changes were seen in these patients.

\section{ANGINAL PATIENTS}

The maximum heart rates achieved in these patients were 115 to 168 beats/minute (mean 137 beats/ minute). The mean work load was 125 watts at 
PRAECORDIAL EXERCISE MAPPING

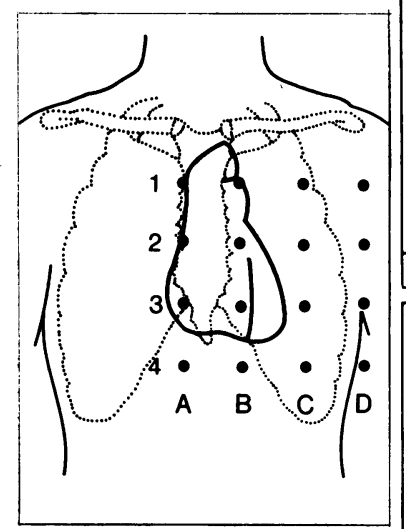

Fig. 3 A typical example of the quality of recording obtained before and immediately after exercise.
$50 \mathrm{rpm}$ for 5 minutes. All 20 patients had significant narrowing $(>70 \%$ ) of one or more of their coronary arteries. The resting electrocardiogram was abnormal in 8 patients and the routine exercise test was abnormal in 17. In all patients ST segment depression was present in 2 or more of the 16 praecordial leads. In the 3 patients with a normal standard exercise test, ST segment depression was present in the infraclavicular (2 patients) and epigastric (1 patient) areas of the surface map.

The sequence of contour maps from a patient showing areas of ST segment depression are shown in Fig. 4. The maximum area of ST segment depression is in the inferior part of the map and extends

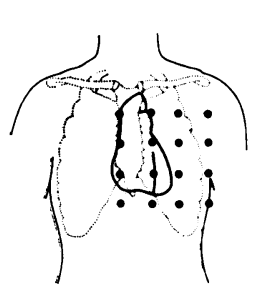

Pre-Exercise

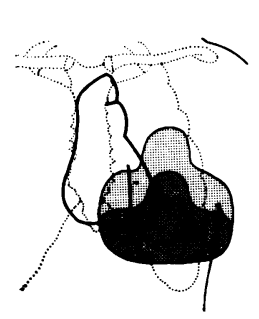

$5 \mathrm{~min}$

Post Exercise ST DEPRESSION

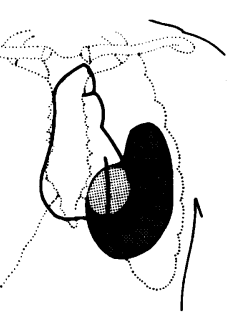

Post Exercise

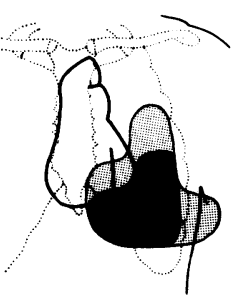

$8 \mathrm{~min}$

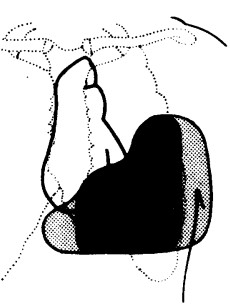

$1 \mathrm{~min}$

Post Exercise

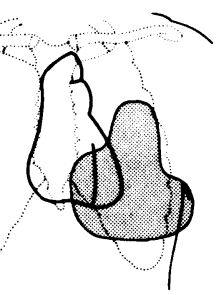

$10 \mathrm{~min}$

Post Exercise

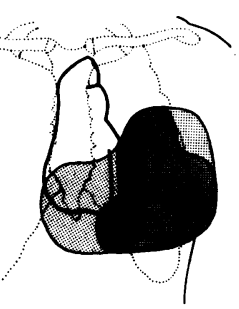

$3 \mathrm{~min}$

Post Exercise

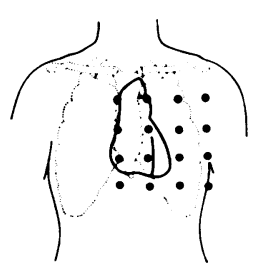

$12 \mathrm{~min}$

Post Exercise

$3 \mathrm{~mm}$
Fig. 4 A typical sequence of contour maps showing the development of $S T$ segment depression after exercise. This patient was found at coronary arteriography to have a severe narrowing of the right and circumflex coronary arteries. 
upwards and to the left. ST segment depression was present immediately at the end of exercise, and both the area and severity increased during the first minute and then decreased spontaneously, returning to the resting state by 12 minutes. This patient's coronary arteriograms showed important lesions of all 3 coronary arteries but the most severe strictures involved the right and left circumflex vessels.

\section{REPRODUCIBILITY}

In 5 of the anginal patients a further exercise test was performed on a separate day. All patients were able to reach their previous work load and no significant difference was found in the area and severity of ST segment changes measured on the 2 days. The mean number of positions showing ST segment depression immediately after exercise at the first and second study was 4.6 and $5 \cdot 2$ respectively. Likewise the mean total ST segment depression recorded in the 16 leads at the first study was $7 \mathrm{~mm}$ and at the second study was $7 \cdot 2 \mathrm{~mm}$.

\section{Discussion}

In this study a method for praecordial surface mapping of the exercise electrocardiogram has been described. It was found easy to perform and caused no more discomfort to the patient than a routine exercise test.

A 16-lead system was selected as a manageable number that would cover as many points as possible on the left half of the chest. It was also possible to record each electrocardiographic map rapidly. The press stud electrodes were light, made good contact, and did not fall off (Fluck and Burgess, 1966).

The studies in 5 of the patients with coronary artery disease showed that the technique was reproducible. The area and severity of ST segment depression recorded was similar when the patients were exercised to the same work load on 2 separate days.

This study has shown that distinctive maps can be obtained from different praecordial areas of ischaemia. The increased diagnostic accuracy of this system is as yet uncertain. It has been shown that failure to record leads other than V5 will introduce a negative error of 15 to 20 per cent (Phibbs and Buckells, 1975). Previous workers have shown that 50 to 80 per cent of patients who have at least 50 per cent narrowing of a single coronary artery have at least $1 \mathrm{~mm}$ horizontal ST depression on their exercise electrocardiogram (Mason et al., 1967; Kassebaum et al., 1968; Roitman et al., 1970). Other studies have found a sensitivity of only 33 per cent (Borer et al., 1975). Recording from 16 praecordial positions may reveal areas of ischaemia that are inaccessible to the standard exercise electrocardiogram.

Surface mapping of the exercise electrocardiogram has provided a means of detecting and measuring the time course, severity, and area of praecordial changes that occur in the ST segment on exercise. The relation between abnormalities of the coronary anatomy, reversible disturbances of myocardial perfusion and metabolism, and the projection of electrocardiographic signs onto the chest needs to be investigated. This may provide a useful non-invasive method for assessing medical and surgical treatments in each patient with ischaemic heart disease.

\section{References}

Block, P., Tiberghien, J., Coussaert, E., Lenaers, A., Van Thiel, E., Lebedelle, M., Sunoons, M., and Kornreich, F. (1976). Stress surface mapping: variations with respect to resting isopotential surface maps. In Proceedings 7 th European Congress of Cardiology, Abstract Book I, p. 737. Ciba, Amsterdam.

Borer, J. S., Brensike, J. F., Redwood, D. R., Itscoitz, S. B., Passamani, E. R., Stone, N. J., Richardson, J. M., Levy, R. I., and Epstein, S. E. (1975). Limitations of the electrocardiographic response to exercise in predicting coronary artery disease. New Englandfournal of Medicine, 293, 367-371.

Fluck, D., and Burgess, P. A. (1966). A press-stud electrode for continuous monitoring of the electrocardiogram. Lancet, 1, 1405.

Frank, E. (1956). An accurate, clinically practical system for spatial vectorcardiography. Circulation, 13, 737-749.

Kassebaum, D. G., Sutherland, K. I., and Judkins, M. P. (1968). A comparison of hypoxaemia and exercise electrocardiography in coronary artery disease: diagnostic precision of the methods correlated with coronary arteriography. American Heart Fournal, 75, 759-776.

Kilpatrick, D. (1976). Exercise vectorcardiography in diagnosis of ischaemic heart disease. Lancet, 2, 332-334.

Lanooy, C., and Bonjer, F. H. (1956). A hyperbolic ergometer for cycling and cranking. Fournal of Applied Physiology, 9, 499-500.

Mason, R. E., and Likar, I. (1966). A new system of multiple lead exercise electrocardiography. American Heart fournal, 71, 196-205.

Mason, R. E., Likar, I., Biern, R. O., and Ross, R. S. (1967). Multiple lead exercise electrocardiography. Experience in 107 normal subjects and 67 patients with angina pectoris and comparison with coronary cinearteriography in 84 patients. Circulation, 36, 517-525.

Myers, G. B., and Talmers, F. N. (1955). Electrocardiographic diagnosis of acute myocardial ischaemia. Annals of Internal Medicine, 43, 361-382.

Phibbs, B. P., and Buckells, L. J. (1975). Comparative yield of electrocardiographic leads in multistage stress testing. American Heart fournal, 90, 275-276.

Reid, D. S., Pelides, L. J., and Shillingford, J. P. (1971). Surface mapping of RS-T segment in acute myocardial infarction. British Heart fournal, 33, 370-374.

Roitman, D., Jones, W. B., and Sheffield, L. J. (1970). Comparison of submaximal exercise ECG test with coronary cineangiocardiogram. Annals of Internal Medicine, 72, 641-647.

Scandinavian Committee on ECG classification (1967). The 'Minnesota Code' for ECG classification. Adaption to CR leads and modification of the code for ECGs recorded 
during and after exercise. Acta Medica Scandinavica, Suppl. 481, 1-26.

Selwyn, A. P., Fox, K. M., Welman, E., and Shillingford, J. P. (1978). Natural history and evaluation of $Q$ waves during acute myocardial infarction. British Heart fournal, 40, 383-387.

Selwyn, A. P., Ogunro, E., and Shillingford, J. P. (1977). The natural history and an evaluation of ST segment changes and MB CK release in acute myocardial infarction. British
Heart fournal, 39, 988-994.

Selwyn, A. P., and Shillingford, J. P. (1977). Praecordial mapping of $Q$ waves and RS ratio changes in acute myocardial infarction. Cardiovascular Research, 11, 167-171.

Requests for reprints to $\mathrm{Dr}$ K. M. Fox, Division of Cardiovascular Disease, Royal Postgraduate Medical School, Du Cane Road, London W12 0HS. 